\title{
GEOGRAFIA E POLÍTICA
}

\author{
Paul Claval
}

Por que alguém se torna geógrafo ? Sem dúvida, em virtude da atraçáo pelo desconhecido; pelo fascínio de novos mundos e pela paixão por viagens. Mas também, porque se pertence a um país onde se tem prazer em conhecer os contornos, a riqueza e os trunfos sobre o cenário internacional; porque nele se indaga sobre as possibilidades que tèm de prosperar e porque inquieta-se com as ameaças que vizinhos e concorrentes fazem pesar sobre si. As preocupações políticas permanecem subjacentes nos propósitos dos geógrafos, mesmo quando eles adotam o tom desapaixonado dos professores. Perante muitos, Vidal de la Blache encarna o parti-pris acadêmico de neutralidade mas nāo foi ele mesmo que começou sua carreira com um artigo sobre o impacto da abertura do canal de Suez sobre o Mediterrāneo, a Europa e o cenário politico mundial ? Mais do que ninguém, ele contribui para a fixação da imagem do território francês com seu Tableau de la Géographie en France. Estourou um litígio internacional a propósito das fronteiras da Guiana ? É ele o expert. Alguns anos mais tarde, ele enaltece uma reforma regional destinada a favorecer o desenvolvimento económico do pais. Por ocasiāo da Primeira Guerra mundial, ele se amarra ao destino das provincias anexadas pelo tratado de Frankfurt, a Alsácia e a Lorena, e à fronteira do Sarre. Não seria demais para alguém que às vezes se tentou apresentar como a-político ?

Os políticos vivem na geografia e a aplicam. Se são parlamentares, é preciso que conheçam as atividades de sua circunscrição, que encontrem os notáveis, negociem com os grupos de pressão que ai representam os diferentes interesses economi- cos e com todos os componentes da população. Quando um dia chegam à direção de um partido, têm de rever regióes e departamentos para saber se a opiniāo lhes é favorável ou hostil de designar os candidatos mais aptos a conquistar a vitória e de negociar alianças com outras formaçōes, a fim de assegurar segundos turnos mais fáceis, se o escrutínio ocorrer duas vezes. Os governos seguem a vida interior; preocupam-se com as tensões; tentam acalmá-los e elaboram leis que têm em conta interesses, frequentemente contraditórios, dos diferentes componentes do país. O cenário mundial preocupa-lhes do mesmo modo: com quem aliarse ? Em caso de guerra ou de tensão internacional, como assegurar a segurança dos aprovisionamentos necessários à alimentação e à atividade do pais ? Onde encontrar novas opções às atividades industriais ? Onde instalar os excedentes de população, se o crescimento demográfico ameaçar o nível de vida ? Deve-se buscar uma expansão territorial para recuperar as antigas possessões, consolidar um fronteira frágil, anexar províncias ricas em solo e subsolo?

Os governos dos países democráticos avançados nāo têm a mesma cobiça por terras virgens que aqueles que ocupavam esse lugares há um século. A evolução dos armamentos e os riscos inerentes aos conflitos nucleares aumentaram de tal forma o preço a ser pago por eventuais conquistas, que aprendeu-se a consolidar outras estratégias constituição de conjuntos supranacionais, políticas de abertura económica etc. Os meios da diplomacia mudaram, mas sua dimensão espacial não desapareceu. Em todos os paises, os grandes corpos 
que participam da elaboração de estratégias internacionais desenvolvem suas próprias concepções. Os militares tornaram-se mais sensiveis ao equilibrio das forças e hoje, ao invés da geometria das bases, usam-se vetores' e misseis. Os diplomatas preocupam-se mais em sondar as reações de parceiros ou de eventuais adversários.

As confusōes técnicas impuseram, desde o fim da Segunda Guerra Mundial, uma reavaliação permanente do cenário politico internacional. Por quatro décadas, a guerra fria fixou a atenção sobre os efeitos geoestratégicos da aviação, dos foguetes e da arma atômica. A calota polar deixou de ser uma fronteira segura para seus países lindeiros: é pelas altas latitudes que passam os itinerários mais diretos entre os países temperados; é ao longo do círculo Ártico que devem ser localizadas as linhas de vigilância, destinadas a alertar os dispositivos estratégicos, e onde devem ser instalados os meios de réplica, suficientes para interceptar pelo menos uma parte dos avióes e foguetes inimigos. A fabricaçāo de submarinos nucleares armados de foguetes e ogivas atômicas deu um novo valor aos Oceanos e ao conhecimento dos limites que os separam, porque fica muito mais fácil detectar os navios cuja assinatura sonora se viu reduzida a um sim. ples sopro.

A Queda dos Muros inverteu a ordem das prioridades: os armamento nucleares não desapareceram, mas o risco de um confronto entre os Estados Unidos e a ex-União Soviética já pertence ao passado. A vigilància continua necessária, em vista do número de países que dispõem de armas atômicas e dos que chegarão a possui-las, num futuro mais ou menos longínquo. A curto prazo, as armas químicas e biológicas parecem mais temíveis, porque podem ser produzidas por paises pouco industrializados e com pouco domínio sobre tecnologias sofisticadas.

Apesar dessas inquietações geoestratégicas que permanecem, são os problemas econômicos e culturais que tendem a ocupar o centro das atenções. Os custos de transporte de massa não cessaram de baixar desde a Segunda Guerra Mundial. A revolução do container fez desaparecerem as rup- turas de carga, outrora tão dispendiosas, e tornou inúteis os intermediários que se interpunham entre os produtores e distribuidores finais; a revolução logistica que daí resulta, permite às firmas garantirem, elas mesmas, a distribuição dos produtos sobre o conjunto do planeta. Graças aos computadores e às redes de telecomunicação que se acoplam, tornou-se fácil transmitir qualquer volume de informações, a preços baixos, para qualquer parte do mundo. As fases de transformação industrial das fileiras produtivas permaneciam circunscritas em circulos de trezentos ou quatrocentos quilómetros de diâmetro. Hoje elas andam efervescentes, já que uma usina de montagem pode ficar em contacto permanente com seus fornecedores, sejam quais forem suas localizações. Entretanto, permanece uma dificuldade: no momento das decisões importantes, é preciso encontrar-se com os parceiros. As viagens se fazem de avião. Para não se estender, os Estadosmaiores, sedes sociais, serviços comerciais e serviços financeiros de firmas se instalam em cidades grandes, equipadas de um aeroporto conectado com todas as aglomerações em nivel mundial. A mundialização da economia vai de par em par com o movimento de metropolização.

A globalização da vida econômica fez desaparecer os mercados locais. Os mesmos produtos se impõem por toda parte. As técnicas e o saber desenvolvido para se tirar partido dos recursos locais e responder a demandas específicas são desvalorizados. Como as populações serviam-se, espontaneamente, de tudo o que diferenciava seu modus vivendi de seus vizinhos na construção de identidades, elas têm o sentimento de estarem sendo despojadas de uma parte essencial de seu ser, pelo progresso técnico. Buscando evitar perdas, elas valorizam tudo o que, em seu patrimônio, não fica diretamente ameaçado. É com muito respeito que ora se contemplam os testemunhos do passado: quanto mais frágeis e ameaçadas forem as culturas, mais as pessoas a ele se ligam. Movimentos regionalistas ou nacionalistas tiram partido de suas lembranças de uma história dividida, para cimentar a unidade dos grupos de hoje. Em outros lugares, é na fé religiosa não contaminada pela 
modernidade que se busca a salvação: é daí que vem o sucesso dos fundamentalistas.

O cenário mundial evolui rapidamente sob impacto da evolução das técnicas de armamentos, de transporte e de comunicação. Será que os políticos esperam que os geógrafos Ihes ajudem a compreender o que está acontecendo e a lhes proporem novas estruturas adaptadas às condiçōes atuais? Aparentemente, não. De Hiroshima ao fim da Guerra Fria, os homens de Estado só precisaram, para analisar o equilibrio das forças presentes no mundo, da opinião de especialistas em armas nucleares, de foguetes e de equipamentos eletrônicos de detecção. Desenvolveram-se, assim, uma geoestratégia e uma geopolítica de militares que construíram todas outras abordagens por mais de uma geração.

De há tempos, os serviços diplomáticos têm o hábito de analisar as relações de um país com seus vizinhos e de levar em conta tudo o que ele pode tirar das relações internacionais que mantêm. Sabem em qual direção convém desenvolver uma política de expansão ou de anexação territorial. Inquietam-se com a reação dos Estados estrangeiros, de sua suscetibilidade e do estado da opiniāo pública.

O mundo político não esperou o impulso da geografia moderna para analisar as forças existentes nas relações entre os Estados e definir doutrinas de ação: graças à sua experiència, os homens de Estado elaboram idéias sobre as grandes leis da geografia política e aprenderam a praticar a geopolítica, enquanto reflexão sobre estratégias desejáveis, antes de agir. A preocupaçào de fazer face a novas situaçōes estimula a reflexão nesses campos. As grandes administrações têm, em seu seio, células de análise. Os diplomatas procuram compreender por que seus papéis tendem a diminuir, e a modificarem seus modos de intervenção, para dar mais força à sua açāo. Os serviços econômicos se perguntam sobre as consequências da mundializaçăo. Em um mundo onde as desordens territoriais tornaram-se dificeis, os Estados aprenderam a adotar outras estratégias. Unem suas forças para enfrentar as crescen- tes concorrências, criam zonas de livre troca, de uniōes alfandegárias e de mercados comuns. Aprendem a renunciar a fraçóes cada vez mais importantes de soberania para permitir, a cada conjunto territorial, encontrar um lugar no cenário mundial. O fim é proporcionar, às populaçōes que aí vivem, os meios de contribuir, suficientemente, à atividade económica mundial, para se alimentar, dar trabalho a todos e ver melhorar os níveis de vida.

É dos serviços de coleta de dados e de reflexăo que bem frequentemente dependem os Estados ou os organismos supranacionais - tais como a ONU, a UNESCO, a OCDE e a União Européia que os geógrafos colhem dados e explicações, com os quais alimentam seus trabalhos. Quer dizer então que, no mundo atual, os geógrafos nada tēm a dizer de pertinente sobre o cenário político, nada a ensinar aos governantes ou aos administradores?

Os militares, diplomatas ou responsáveis pela economia nào costumam ter tempo de recuo face à realidade. Eles procuram soluçōes de hoje para problemas prementes e logo renunciam a analisar situaçōes, mudando de escala temporal ou espacial. É o que a pesquisa universitária faz à vontade.

Os homens pertencem a grupos enraizados; seus comportamentos nào dependem somente de sua situação objetiva e de seus interesses economicos. Frequentemente, possuem um forte componente local. Este é um dos primeiro resultados obtidos pela geografia política: André Siegfried ${ }^{2}$ demostrava, desde 1913, a surpreendente permanência de implantação de partidos políticos de direita na França do Oeste. Très quartos de séculos mais tarde, suas observações nunca foram desmentidas, mesmo se a especificidade dessas regióes tenha progressivamente se atenuado. É do lado da história, do choque de época revolucionàrio e da guerra de Vendée ${ }^{3}$ que geralmente se volta para compreender a singularidade de atitudes que, aliás, nada justifica. Mas esta história seria logo esquecida se nảo tivesse permanecido memória viva, se não tivesse suscitado uma desconfiança profun- 
da perante todas instituições republicanas, da escola em particular, e não tivesse pactuado com um catolicismo de combate. Num registro vizinho, Emmanuel Todd sublinha um bocado de influência persistente das estruturas familiares sobre os comportamentos politicos, em quase toda Europa.

As pesquisas dos quinze últimos anos retomam, incessantemente, os componentes locais da vida social e política. Mesmo países de sociedade profundamente bem unificada e estandartizada, como os Estados Unidos, não escapam desses efeitos.

Quase todos geógrafos do começo do século achavam que seus papéis consistissem em sublinhar o peso dos revéses naturais na vida social. Ligavam-se à fertilidade do solo e à sua aptidão em garantir a vida de populaçōes numerosas. Inquietavam-se com os recursos minerais, com a abundância de reservas de hulha, com a riqueza das jazidas de ferro. Sabiam que, com certeza, o comércio e as trocas liberam os grupos de uma submissão exagerada das possibilidades do meio onde estão instalados, mas isto não bastava para acalmar suas inquietudes. A guerra pairava sempre ameaçadora. Como um pais muito dependente de suas importaçōes poderia sobreviver um longo conflito ? Não seria justamente sabedoria dispor, no próprio lugar, de recursos suficientes para permitir à máquina econômica continuar girando, mesmo que num ritmo um pouco reduzido?

Alguns recursos não viajam. Assim acontece com a água quando muito podia-se levar, via canais de irrigação, os caudais alimentados pelas neves das montanhas ou pelas abundantes chuvas dos trópicos úmidos a cinqüenta, cem, duzentos ou trezentos quilometros do lugar de coleta. Nos paises áridos, o imperativo da água parecia sumamente essencial.

Três quartos de século mais tarde, os progressos técnicos em transporte permitiram reduzir a poucas coisas, o peso dos recursos naturais no sucesso econômico. Desfeito pela guerra, o Japão, com uma base agrícola de extensão limitada, pouco carvão ainda por cima de qualidade mediocre - e sem petróleo, em vinte e cinco anos tornou-se a segunda potência econômica do planeta. Seus altos fornos queimam o coque fabricado à partir do carvão importado da Austrália, da África do Sul ou do Canadá e empregam minerais de ferro provenientes da Austrália, da Venezuela, do Brasil, da Libéria ou da Mauritânia.

Quer dizer então que os problemas ecológicos desapareceram ? Náo, mas eles mudaram de tipo. Graças aos transportes, a produtividade dos ecossistemas locais ou a ausência de energia fóssil no subsolo de um pais cessam de ser fatores limitantes. Hoje é possível acumular homens, formas de energia concentrada e equipamentos produtivos em qualquer ponto do planeta. O único limite advém da capacidade dos ecossistemas em receber residuos sólidos a serem reciclados nas águas usadas e o gás emitidos pelas casas, máquinas e veículos. Nas zonas rurais, frequentemente, as atividades fora do solo geram graves poluiçōes. Em quarenta anos, a Bretanha tornou-se uma das partes mais produtivas da França, do ponto de vista agricola: com suas criaçōes industriais, contribui copiosamente à produção européia de aves, ovos, carne de porco e de bezerro. A abundância de restos, adubo de porco ${ }^{4}$ em particular, traduz-se, infelizmente, por uma concentração de nitrato tão forte nos lençóis dos cursos de água, que todo o sistema de produçào é questionado, fazendo com que ocorra um processo de desconcentração de atividades. Há niveis de concentraçāo que não devem ser ultrapassados: os políticos começam a tomar consciência. Os geógrafos podem ajudar a melhor compreender a atual dinâmica e a analisar, ao mesmo tempo, as dimensões sociais, regionais e globais dos atentados aos equilibrios naturais.

Ainda subsistem certos revéses naturais, de estilo tradicional: em particular, os ligados à raridade da água. Os Estados afetados pela aridez ou ameaças são bem conscientes disso. Os geógrafos podem, inclusive neste campo, adiantar a reflexão em vista da manutenção da paz a longo prazo.

A globalizaçāo produz tantos distúrbios encadeados, que nem sempre os políticos conseguem reconhecer à boa medida. A concorrência dos paises recentemente industrializados não provêm só da 
baixa de preço dos fretes, da aceleraçāo das viagens e da eficácia das telecomunicaçōes. Ela não teria sido possivel sem a evolução que tornou as técnicas mais cientificas. A maior parte das de ontem só podia adquiri-las por aprendizagem, nos contactos com os núcleos onde já existiam fabricações: os países avançados beneficiavam-se de um monopólio do trabalho industrial. Este foi perdido, na medida em que a pesquisa avançava entre si e a instrução se difundia pelo Terceiro Mundo. A nostalgia nāo é admissivel: os produtores europeus, americanos e japoneses nāo mais conhecerão situaçōes delicadamente protegidas que antes lhes pareciam evidentes. Os politicos deviam compreender que nenhum país pode esquivar-se das novas condiçōes de concorrência.

Graças à revoluçāo dos transportes rápidos e das telecomunicações, as firmas tornaram-se livres para distribuir, à vontade, os estabelecimentos produtores. Elas respondem às pressōes que os Estados lhes submetem, deslocalizando-se. As naçōes perderam o domínio de suas economias: as medidas que tomam tornam-se contra-produtivas, desde que ameacem o equilíbrio das empresas.

A soberania dos Estados se vẽ entāo erodida pelo alto - já que convém criar conjuntos pluri-nacionais mais adaptados às novas condiçōes da concorrência e por baixo, porque cidades e regióes, que as políticas nacionais não protegem mais, lutam pelo direito de praticar políticas de seduçāo junto aos investidores.

No interior dos Estados, exaurem-se as estruturas regionais hierarquizadas, apoiadas em redes urbanas regulares: desde então, contam apenas as metrópoles suficientemente poderosas para serem conectadas, por voos diretos, com todos os centros de controle e de impulso da economia global e as cidades que lhe são bem religadas, para em torno delas gravitar. As políticas de planejamento, tais como se aprendeu a conceber há uma geração, não mais se adaptam ao mundo atual.

A geografia oferece ainda mais aos políticos: situando-se em outra escala de tempo - a das longas evoluções e buscando a economia-mundo em seu conjunto, ela lembra que o destino das formaçóes políticas é indissociável de sua contribuiçāo com os circuitos de produção e de troca internacionais. Durante muitos séculos, os Estados instalados no centro do mercado mundial, na Europa e depois na América do Norte e no Japão, puderam se organizar em espaços nacionais, dispor de finanças abundantes, criar exércitos e marinhas eficazes, e assim assegurar seu dominio coletivo global. Na periferia, as condições eram radicalmente diferentes: a mediocridade dos ganhos impedia a realizaçào de retiradas de capital importantes. O Estado não podia reunir os meios necessários para assegurar seu controle no interior (falta de uma administração regular) e sua segurança exterior (falta de poder equipar e pagar regularmente um exército, uma marinha e mais tarde, uma aviaçāo).

As condições nas quais vivemos são diferentes. A metropolizaçāo tende a melhor repartir as funções de direção e controle, já que sāo divididas entre todas as metrópoles do conjunto mundial. Mas a acumulação de homens nas grandes cidades do Terceiro Mundo não as transforma, automaticamente, em organismos urbanos eficazes. Sem um mínimo de serviços públicos e segurança, não é possível desenvolver-se, no entorno, outras produçōes além de energia e matérias primas.

A mutação em curso vai mais longe: é o funcionamento dos Estados avançados que está ameaçado: as deslocalizações reduzem os impostos que entram; as máquinas administrativas criadas pelos Estados de bem-estar são tão pesadas, que esses são obrigados a suspender suas retiradas de capital a todo momento, acelerando assim o êxodo de empregos. Se renunciam aos excessos de proteção social, tal como a Grã-Bretanha da Sra. Thatcher ou na Nova Zelāndia, sāo todos os mecanismos de regulação social que entram em pane.

A mundialização tem outras conse-quências que os geógrafos costumam sublinhar: ela multiplica os contactos diretos entre os povos. As pessoas viajam mais, aprendem a se conhecer mas também, que lástima, a reforçar os clichès de idéias recebidas. Para uma empresa ou associação fica fácil manter serviços ou antenas no estrangeiro. As relaçōes internacionais pertencem cada vez mais 
à esfera do privado. Isto fica bem claro no campo filantrópico ou cultural: os órgãos não governamentais tornaram-se parceiros essenciais de todas as relaçōes entre os países ricos e os que ainda sofrem de pobreza.

O mundo no qual nós entramos se estrutura em torno de redes internacionais. Sempre houve diásporas. As que se multiplicam hoje não são mais feitas de células que mal se comunicam entre si. Visando manter contactos, as comunidades dispersas tiram partido dos voos charters e das telecomunicaçōes. Em um mundo que precisa de intermediários ambivalentes ${ }^{5}$ em muitas áreas culturais ou linguísticas, elas são chamadas a bancar, cada vez mais, o papel de suporte de grandes redes. As minorias estrangeiras sabem, desde então, que podem reivindicar status mais vantajosos que os que lhe eram outorgados, quando não participavam tão diretamente da vida internacional.

Deste modo, os geógrafos podem mostrar aos politicos todas as implicações das mutaçōes em curso. As transformações do cenário internacional
Ihes dão, ao mesmo tempo, um outro papel: num mundo mais aberto, onde grande parte das interações é negócio de empresas ou associaçōes, os cidadãos participam mais diretamente da vida internacional do que outrora. No passado, eles votavam, depois viam seus eleitos agir. Hoje, eles in tervêm diretamente no estrangeiro, tanto no campo económico como no cultural; as organizaçōes e as empresas que criaram ou nas quais trabalham, podem se desinteressar pelo contexto político dos lugares onde se implantaram. Com frequência e à contravontade, elas se tornam importantes elementos da vida política local.

Os geógrafos já nāo têm unicamente o dever de esclarecer os responsáveis políticos. Eles devem, cada vez mais, elucidar a populaçāo sobre quais sāo as chances de ação e também suas responsabilidades num mundo ora ampliado. Sem dúvida, é por conta disso tudo que a geografia nunca teve tanta necessidade de ser política.

Tradução de Eduardo Yázigi
1 Vetores são veículos capazes de transportar carga nuclear. N.T.

2 André Siegfried (1875-1959), geógrafo e sociólogo francês, é autor de numerosos trabalhos de sociologia política e de geografia econômica; foi membro da Academia Francesa. N.T.

3 Trata-se de uma insurreição contra-revolucionária ocorrida em 1793, entre os camponeses da Bretanha do Poitou e do Anjou, por uma Constituição civil do clero. Após alguns sucessos em
Fontenay, Cholet e Saumur, os camponeses da Vendée foram encurralados na margem esquerda do Loire. Em 1795 o General Hoche outorgou liberdade de culto, pacificando completamente a região. N.T.

4 "Lisier" no original: palavra derivada de um dialeto suisso, significando uma mistura de excrementos de porcos, com os quais se obtém a purina. N.T.

5 "Travailler à cheval". no original. Isto é, ter um pé em cada lado. N.T. 